\title{
A biometric iris recognition system based on principal components analysis, genetic algorithms and cosine-distance
}

\author{
V. Nosso ${ }^{1}$, F. Garzia ${ }^{1,2}$ \& R. Cusani ${ }^{1}$ \\ ${ }^{I}$ Department of Information, Electronics and \\ Telecommunication Engineering - SAPIENZA - University of Rome, Italy \\ ${ }^{2}$ Wessex Institute of Technology, UK
}

\begin{abstract}
Iris recognition is regarded as the most reliable and accurate biometric identification system available. The present work involves the development of a novel technique in order to improve the performance of iris recognition systems. We have used for our experiments a publicly available iris recognition system. Tests on CASIAv3 image database have resulted in a $2 \%$ accuracy improvement with respect to traditional methods; a significant one in iris recognition.
\end{abstract}

Keywords: iris recognition, PCA, genetic algorithms, cosine distance, biometrics.

\section{Introduction}

The iris, that is the unique human internal organ visible outside, is a sort of muscle that trimmers the pupil diameter, controlling the light amount that gets into the eye, reaching the retina where it is converted into electrical pulses that reach the brain to be analysed and understood. The mean iris diameter is equal to 12 millimetres while the diameter of the pupils, varies from $10 \%$ and $80 \%$.

The iris is a stratified structure, composed by a layer of strongly pigmented epithelial cells that do not allow light penetration, a layer of muscles that trimmer the pupil opening, a layer of blood vases enriched by radials grooves that are little folds whose depth varies as a function of pupil dilatation.

Each iris is characterized by a complex pattern whose combination of randomness and complexity gives it a mathematical uniqueness with a collision 
probability just equal to zero. In fact, the two iris patterns of the same person are different and independent and the same is valid for the eyes of the homozygote twins. This is due to the fact that iris patterns are epigenetic, since they start from a given genetic configuration and they develop during pregnancy independently from the genetic component.

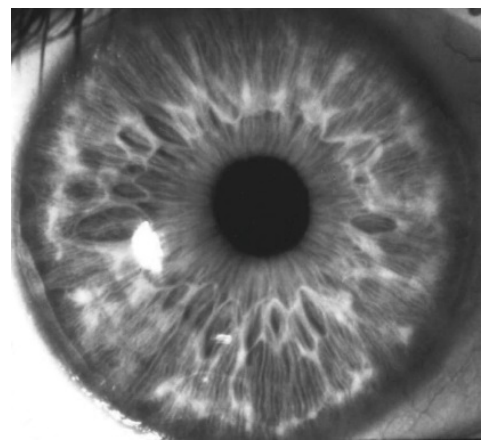

Figure 1: A picture of an iris.

It has been calculated [1] that the probability of existence of two similar iris patterns is about $10^{-78}$

The experiments related to the determination of the statistical properties of iris patterns $[2,3]$ have shown that they are characterized by a binomial distribution with $\dot{\rho}=0.5$ and 249 degrees of freedom that confirm that the collision probability of two iris pattern on the same iriscode is about $10^{-78}$.

The iris pattern, once stabilized, remains the same for the whole life unless some particular degenerative pathologies occur.

The present work proposes a novel technique for improving iris recognition systems accuracy through principal component analysis (PCA), genetic algorithms (GAs) and cosine-distance (CD).

A publicly available iris recognition system [4] has been used for system developing and comparative testing. Tests on CASIAv3 [5] image database have resulted in a $2 \%$ accuracy improvement with respect to existing systems that represents a significant result in iris recognition field characterized by high accuracy and recognition rate.

\section{Iris acquisition}

During iris acquisition, disturb such as cilia and eyelid can partially occlude the image (as shown in fig. 2), and it is necessary to apply a proper mask to avoid a noisy acquisition.

After this operation it is necessary to make a proper segmentation to individuate the internal and external contours of the iris. 


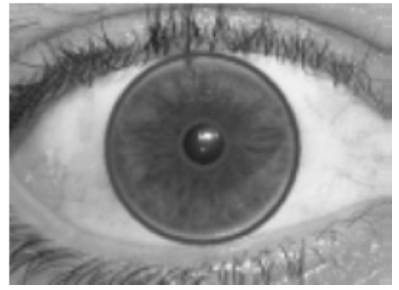

(a)

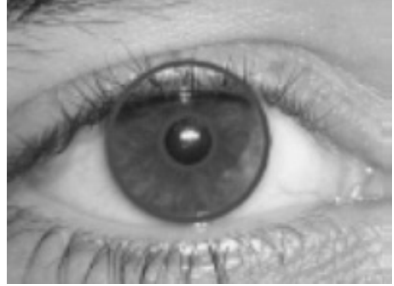

(b)

Figure 2: (a) Clear iris image; (b) partially occluded iris image.

\section{Iris normalization}

Once the external and the internal contours of the iris are individuated, a proper transformation from polar coordinates $(r, \theta)$ to Cartesian coordinates $(x, y)$ is made using the following [6]:

$$
\begin{aligned}
& x(r, \theta)=(1-r) x_{p}(\theta)+r \cdot x_{i}(\theta) \\
& y(r, \theta)=(1-r) y_{p}(\theta)+r \cdot y_{i}(\theta)
\end{aligned}
$$

where $\quad r \in[0,1], \quad \theta \in[0,2 \pi], \quad\left(x_{i}(\theta), y_{i}(\theta)\right)$ and $\left(x_{p}(\theta), y_{p}(\theta)\right)$ are the coordinates of the iris and the pupil, respectively, along the direction individuated by $\theta$. In this way, the annular structure of the iris becomes a normalized rectangular structure (as shown in fig. 3 ).
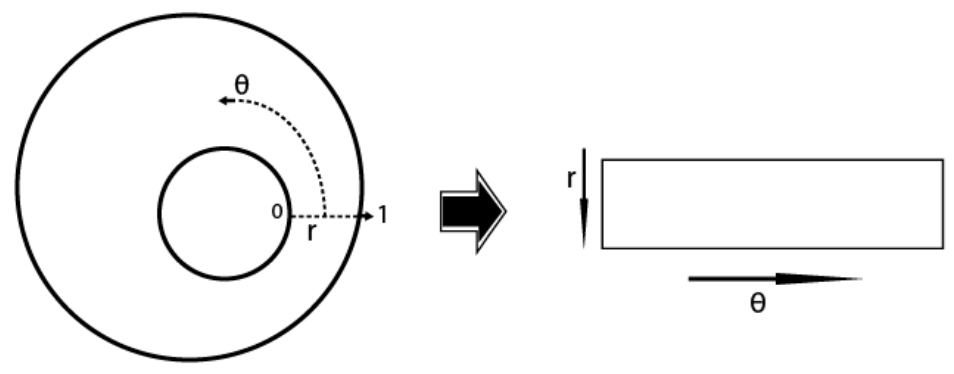

Figure 3: Normalization of the iris structure.

\section{Iris coding}

Once the iris is normalized, it is necessary to code it.

From this point of view, a proper binary code is derived quantifying the phase response of a texture filter [6], represented by the $2 \mathrm{D}$ Gabor filter that is: 


$$
H(r, \theta)=e^{-j \omega\left(\theta-\theta_{0}\right)} e^{-\left(r-r_{0}\right)^{2} / \alpha^{2}} e^{-j\left(\theta-\theta_{0}\right)^{2} / \beta^{2}}
$$

where $\alpha$ and $\beta$ vary with an inverse proportion with respect to the frequency $\omega$ to generate a set of quadrature pair frequency-selective filters centred in the position $\left(r_{0}, \theta_{0}\right)$.

Then the angle of the phasor represented by complex coefficient over 4 levels (one for every quadrant of the complex plane) is quantified, generating for every $\left(r_{0}, \theta_{0}\right)$ a couple of bit $\left(h_{\Re}, h_{\mathfrak{J}}\right)$ according to:

$$
\begin{aligned}
& h_{\Re}=\left\{\begin{array}{lc}
1 & \operatorname{Re}\left(\iint_{\rho \psi} e^{-j \omega\left(\theta_{0}-\psi\right)} e^{-\left(r_{0}-\rho\right)^{2} / \alpha^{2}} \times e^{-j\left(\theta_{0}-\psi\right)^{2} / \beta^{2}} I(\rho, \psi) d \rho d \psi\right) \geq 0 \\
0 & \text { otherwise }
\end{array}\right. \\
& h_{\mathfrak{I}}=\left\{\begin{array}{lc}
1 & \operatorname{Im}\left(\iint_{\rho \psi} e^{-j \omega\left(\theta_{0}-\psi\right)} e^{-\left(r_{0}-\rho\right)^{2} / \alpha^{2}} \times e^{-j\left(\theta_{0}-\psi\right)^{2} / \beta^{2}} I(\rho, \psi) d \rho d \psi\right) \geq 0 \\
0 & \text { otherwise }
\end{array}\right.
\end{aligned}
$$

From eqs (3), it is possible to see that every bit represents the sign of the imaginary or real part of the projection of a location on the adopted filter.

It is evident that only phase information is considered since this information are more significant with respect to the amplitude information that depends on the contrast, the light and the camera gain.

The compensation of the eventual angular shift is made during the comparison phase by means of a circular shifting of the code since this operation corresponds to an angular rotation of the image. At the end of the operation, the code that gave the best score is considered since it corresponds to the best alignment.

\section{The principal components analysis (PCA)}

The principal components analysis (PCA) is a well-used technique for the selection and reduction of the dimension of a set of features. It is based on the correlation principle that allows us to find an orthogonal projection base that allows a reduction of the dimension of features arrays and the reduction of the features themselves.

In our case, PCA is used to calculate the projections on the axes in the multidimensional space of the features considering the differences of the iris samples that are in the database.

The used PCA procedure allows a good generalization capability in the reconstruction of a signature when the latter is compared with another signature that has not been used in the training phase. 


\section{Genetic algorithms (GAs)}

Genetic algorithms offer the great advantage of evolving their behaviour to match with the behaviour of the final users, using a mechanism that is very similar to the one used by nature. Different genetic algorithm can be used to achieve the desired purpose, each characterised by peculiar features.

Genetic algorithms are considered wide range numerical optimisation methods, which use the natural processes of evolution and genetic recombination. Thanks to their versatility, they can be used in different application fields.

GAs are particularly useful when the goal is to find an approximate global minimum in a high-dimension, multi-modal function domain, in a near-optimal manner. Unlike the most optimisation methods, they can easily handle discontinuous and non-differentiable functions.

\section{The proposed system}

The proposed system applies the PCA, the GAs and the Cosine distance in different phase of the process to increase the recognition accuracy with respect to the existing systems.

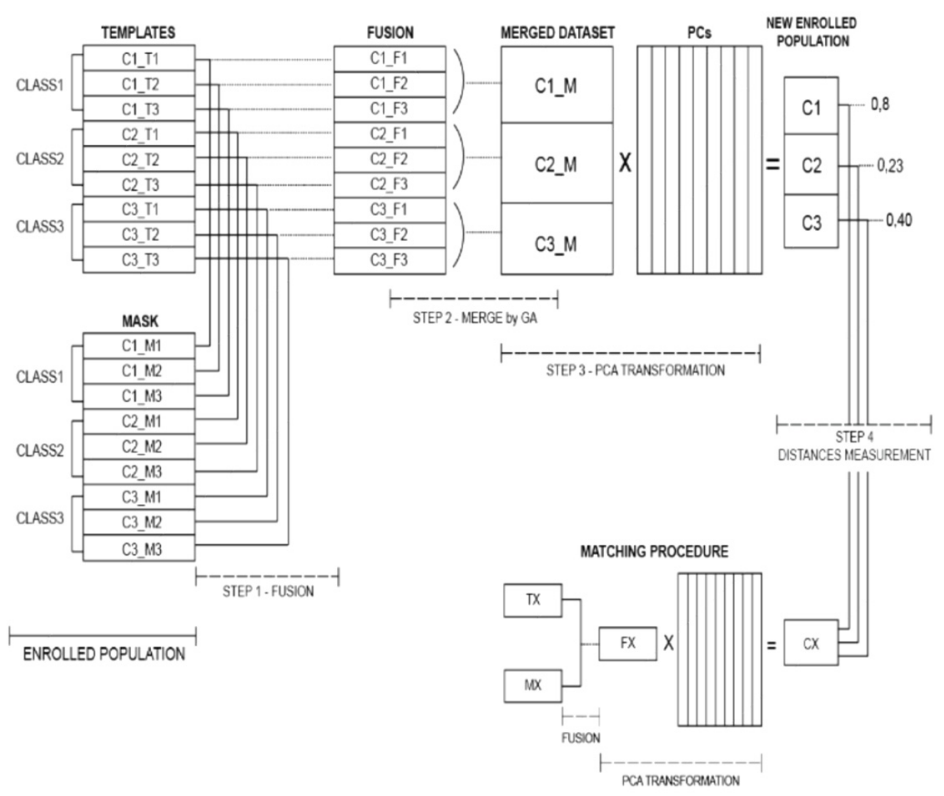

Figure 4: Scheme of the proposed system. 
During the step 1, every iris template of each class is associated a proper mask used during the segmentation phase, to avoid losing precious information, the mask is fused with the template itself provided that the mask does not cover more than $30 \%$ of the iris. The fusion operation in made in a simple way: if a binary value of both templates and mask is equal to 1 , the final value is equal to 0.5 , otherwise the value of the templates remains unchanged $(0,1)$. In this way a new fusion template composed by $(0,0.5,1)$ is generated, considering also the masking effect of celia and eyelid.

During the step 2, the dataset, composed by different pre-processed vectors per class, is processed to obtain a single representative vector per class. The most useful tool is represented by genetic algorithms (GAs).

In fact, since each class is represented by a certain number of templates of the same iris (that in our case is equal to 3), if PCA is applied to all classes, not only the inter-classes differences are exalted but also the intra-classes differences are exalted, leading to possible problem in the recognition phase.

For this reason, before the PCA phase, a proper merging phase, to obtain a unique vector representative of the all vectors that compose the class itself is applied.

After different attempts, the fitness function (to be minimized) has been chosen to be:

$$
\sqrt{\text { intramean }}-\text { extramean }
$$

where intramean and extramean are, respectively, the intra-class mean of the distances and the extra-class mean of the distances obtained from the considered vector over the database in the actual state of processing. The square root operated on the first term is due to the need to individuate the vector that better represents the considered class and for this reason it is necessary to give more importance to the similarity related to the template belonging to the same class more that to the non-similarity between vectors belonging to different classes. Further, the PCA tends to exalt the difference between vectors belonging to different classes. For this reason, a fitness function that balance the above effect is considered.

During the step 3, once that each class is represented by a unique vector, thanks to the GAs computation of step 2, a PCA transformation is applied to increase the differences between the different classes and reduce the dimensionality of the space where the different vectors can be located. The transformation is done through a rotation of the referring system based on the main components individuated by means of the PCA. The same transformation is done on the test template during the comparison phase to project them on the same referring system.

During the step 4, a proper distance metric to calculate the distance between the templates is used. Since after the PCA transformation the templates are not more binary, it is not possible to use the Hamming distance. From this point of view, the cosine distance has been used since it is able to measure the degree of similarity more that the degree of difference such as Euclidian distance. The similarity is defined as: 


$$
\text { similarity }=\cos (\theta)=\frac{A \cdot B}{\|A\|\|B\|}
$$

where A and B are the two considered vectors (or templates).

Since it represents the angle between the two vectors, it is evident that is measure the "direction similarity".

The cosine distance is therefore defined as:

$$
1-\cos \left(W_{1}, W_{2}\right)=1-\frac{\sum_{i=1}^{n} p_{i} q_{i}}{\sqrt{\sum_{i=1}^{n} p_{i}^{2} \sum_{i=1}^{n} q_{i}^{2}}}
$$

where $\mathrm{p}_{\mathrm{i}}$ and $\mathrm{q}_{\mathrm{i}}$, are the components of templates $\mathrm{W}_{1}$ and $\mathrm{W}_{2}$ respectively.

It is now necessary to choose a proper threshold to be used in the comparison phase. In this case, the original database is considered, calculating all the distances between every training template and every class (that is the vector that, after the above operation, represents each class). In this way, a couple of distribution (intra-class and extra-class) is obtained. The segment that connects the mean of the two distributions is divided into 100 sub-segments and, for every value individuated on the extremes, a proper threshold of the same value is individuated. The accuracy (defined as $100-((\mathrm{FP} \%+\mathrm{FN} \%) / 2)$ where $\mathrm{FP} \%$ are the false positive in percentage and FN are the false negative in percentage), calculated using this threshold over the distributions, can be chosen as the one that has produced the best results overall.

\section{Results}

The CASIAv3 database [5] has been used that has been divided into 3 database composed by 60 classes composed by 7 images each (dataset 60-7), 100 classes composed by 7 images each (dataset 100-7), 200 classes composed by 7 images each (dataset100-7).

We first randomly selected three templates for every class to represent the class itself: as consequence, we divided the dataset in two subsets, the enrolled set, which contains these templates, and the test set, containing the templates not selected to be enrolled.

As a first step, we analysed the enrolled set: matching every possible pair of templates belonging to the set we extracted distances distribution; we then searched for the threshold which gave the best accuracy, obtaining the results shown in table 1.

After enrolled population analysis we produced a new couple of distributions (intra/extra class, as usual) matching every template in the enrolled set with every template in the test set; we then use the previously selected threshold to calculate the accuracy on these distributions (we also searched iteratively for the ideal threshold to apply on these distributions), obtaining the results shown in table 2 . 
Table 1: Enrolled population analysis (Hamming distances).

\begin{tabular}{|l|l|l|l|}
\hline & Dataset60-7 & Dataset100-7 & Dataset200-7 \\
\hline $\begin{array}{l}\text { Distribution } \\
\text { features }\end{array}$ & & & \\
\hline Intra-class mean & 0.3 & 0.29516 & 0.30111 \\
\hline Extra-class mean & 0.46998 & 0.47039 & 0.47026 \\
\hline Intra-class variance & 0.0037689 & 0.0032847 & 0.036776 \\
\hline Extra-class variance & 0.00024137 & 0.0021465 & 0.0022221 \\
\hline Classification rates & & & \\
\hline $\begin{array}{l}\text { Best accuracy found } \\
\text { (for threshold) }\end{array}$ & $\begin{array}{l}97.0778 \% \\
(0.41728)\end{array}$ & $\begin{array}{l}97.6616 \% \\
(0.4213)\end{array}$ & $\begin{array}{l}96.5504 \% \\
(0.4296)\end{array}$ \\
\hline $\begin{array}{l}\text { Intra good } \\
\text { classifications }\end{array}$ & $\begin{array}{l}170 \text { on } 180 \\
(94.44 \%)\end{array}$ & $\begin{array}{l}287 \text { on } 300 \\
(95.66 \%)\end{array}$ & $\begin{array}{l}565 \text { on } 600 \\
(94.16 \%)\end{array}$ \\
\hline $\begin{array}{l}\text { Extra good } \\
\text { classification }\end{array}$ & $\begin{array}{l}15884 \text { on } 15930 \\
(99.7 \%)\end{array}$ & $\begin{array}{l}44397 \text { on } 44550 \\
(99.6 \%)\end{array}$ & $\begin{array}{l}17791 \text { on } \\
179100 \\
(98.93 \%)\end{array}$ \\
\hline
\end{tabular}

Table 2: $\quad$ Enrolled vs. test statistics (Hamming distances).

\begin{tabular}{|l|l|l|l|}
\hline & Dataset60-7 & Dataset100-7 & Dataset200-7 \\
\hline $\begin{array}{l}\text { Distribution } \\
\text { features }\end{array}$ & & & \\
\hline Intra-class mean & 0.31433 & 0.30869 & 0.31516 \\
\hline Extra-class mean & 0.47304 & 0.47338 & 0.47344 \\
\hline Intra-class variance & 0.0036829 & 0.0031889 & 0.0037369 \\
\hline Extra-class variance & 0.00020572 & 0.00018924 & 0.0001912 \\
\hline Classification rates & & & \\
\hline $\begin{array}{l}\text { Accuracy found (for } \\
\text { threshold) }\end{array}$ & $\begin{array}{l}96.1982 \% \\
(0.41728)\end{array}$ & $\begin{array}{l}97.4731 \% \\
(0.4213)\end{array}$ & $\begin{array}{l}96.5955 \% \\
(0.4296)\end{array}$ \\
\hline $\begin{array}{l}\text { Intra good } \\
\text { classifications }\end{array}$ & $\begin{array}{l}666 \text { on } 720 \\
(92.5 \%)\end{array}$ & $\begin{array}{l}1141 \text { on } 1200 \\
(95.08 \%)\end{array}$ & $\begin{array}{l}2248 \text { on } 2400 \\
(93.666 \%)\end{array}$ \\
\hline $\begin{array}{l}\text { Extra good } \\
\text { classification }\end{array}$ & $\begin{array}{l}42436 \text { on } 42480 \\
(99.9 \%)\end{array}$ & 118637 on & 475328 on \\
& 118800 & 477600 \\
Ideal rates & $(99.86 \%)$ & $(99.5243 \%)$ \\
\hline $\begin{array}{l}\text { Best accuracy found } \\
\text { for threshold) }\end{array}$ & $\begin{array}{l}96.6066 \% \\
(0.43971)\end{array}$ & $\begin{array}{l}97.7163 \% \\
(0.4388)\end{array}$ & $\begin{array}{l}96.8401 \% \\
(0.4386)\end{array}$ \\
\hline $\begin{array}{l}\text { Intra good } \\
\text { classifications }\end{array}$ & $\begin{array}{l}686 \text { on } 720 \\
(95.27 \%)\end{array}$ & $\begin{array}{l}1163 \text { on } 1200 \\
(96.9167 \%)\end{array}$ & $\begin{array}{l}2284 \text { on } 2400 \\
(95.166 \%)\end{array}$ \\
\hline $\begin{array}{l}\text { Extra good } \\
\text { classifications }\end{array}$ & $\begin{array}{l}41603 \text { on } 42480 \\
(97.9 \%)\end{array}$ & $\begin{array}{l}117037 \text { on } \\
118800\end{array}$ & $\begin{array}{l}470501 \text { on } \\
477600 \\
(98.516 \%)\end{array}$ \\
\hline
\end{tabular}


Considering the developed system, again, as a first step, we analysed the enrolled set as before: just consider in this case we refer to the "new enrolled population", obtaining the results shown in table 3 .

Table 3: Enrolled population analysis (cosine-distance).

\begin{tabular}{|c|c|c|c|}
\hline & Dataset60-7 & Dataset100-7 & Dataset200-7 \\
\hline \multicolumn{4}{|l|}{$\begin{array}{l}\text { Distribution } \\
\text { features }\end{array}$} \\
\hline Intra-class mean & 0.042722 & 0.057206 & 0.071277 \\
\hline Extra-class mean & 0.73227 & 0.74645 & 0.65646 \\
\hline $\begin{array}{l}\text { Intra-class } \\
\text { variance }\end{array}$ & 0.0055536 & 0.0068622 & 0.0067554 \\
\hline $\begin{array}{l}\text { Extra-class } \\
\text { variance }\end{array}$ & 0.0098361 & 0.0059322 & 0.0042718 \\
\hline \multicolumn{4}{|l|}{$\begin{array}{l}\text { Classification } \\
\text { rates }\end{array}$} \\
\hline $\begin{array}{l}\text { Best accuracy } \\
\text { found (for } \\
\text { threshold) }\end{array}$ & $\begin{array}{l}99.7081 \% \\
(0.38749)\end{array}$ & $\begin{array}{l}99.8064 \% \\
(0.4569)\end{array}$ & $\begin{array}{l}99.6914 \% \\
(0.4399)\end{array}$ \\
\hline $\begin{array}{l}\text { Intra good } \\
\text { classifications }\end{array}$ & $\begin{array}{l}179 \text { on } 180 \\
(99.4444 \%)\end{array}$ & $\begin{array}{l}299 \text { on } 300 \\
(99.6667 \%)\end{array}$ & $\begin{array}{l}597 \text { on } 600 \\
(99.5 \%)\end{array}$ \\
\hline $\begin{array}{l}\text { Extra good } \\
\text { classification }\end{array}$ & $\begin{array}{l}10617 \text { on } 10620 \\
(99.9 \%)\end{array}$ & $\begin{array}{l}29684 \text { on } 29700 \\
(99.9461 \%)\end{array}$ & $\begin{array}{l}119260 \text { on } \\
119400 \\
(99.8827 \%)\end{array}$ \\
\hline
\end{tabular}

After enrolled population analysis we matched every template of this population against every template belonging to the test set (produced as the enrolled was) producing a new couple of distributions; we then used the previously selected threshold to calculate the accuracy on these distributions (we also searched iteratively for the ideal threshold to apply on these distributions), obtaining the results shown in table 4.

From tables 1-4 it is possible to see how the performance of the proposed method are superior with respect to the performances of the classical method.

\section{Conclusions}

In the present work a new technique to improve the performance of iris recognition systems has been studied and tested. We have used for our experiments a publicly available iris recognition system. Tests on CASIAv3 image database have resulted in a $2 \%$ accuracy improvement with respect to traditional methods, a significant one in iris recognition. 
Table 4: Enrolled vs. test statistics (cosine-distance).

\begin{tabular}{|c|c|c|c|}
\hline & Dataset60-7 & Dataset100-7 & Dataset200-7 \\
\hline \multicolumn{4}{|l|}{$\begin{array}{l}\text { Distribution } \\
\text { features }\end{array}$} \\
\hline Intra-class mean & 0.11581 & 0.13958 & 0.18129 \\
\hline $\begin{array}{l}\text { Extra-class } \\
\text { mean }\end{array}$ & 0.72704 & 0.74253 & 0.65458 \\
\hline $\begin{array}{l}\text { Intra-class } \\
\text { variance }\end{array}$ & 0.0094728 & 0.085181 & 0.010802 \\
\hline $\begin{array}{l}\text { Extra-class } \\
\text { variance }\end{array}$ & 0.0098429 & 0.0059258 & 0.0041061 \\
\hline \multicolumn{4}{|l|}{$\begin{array}{l}\text { Classification } \\
\text { rates }\end{array}$} \\
\hline $\begin{array}{l}\text { Accuracy found } \\
\text { (for threshold) }\end{array}$ & $\begin{array}{l}98.697 \% \\
(0.38749) \\
\end{array}$ & $\begin{array}{l}99.2121 \% \\
(0.4569) \\
\end{array}$ & $\begin{array}{l}98.8188 \% \\
(0.4399)\end{array}$ \\
\hline $\begin{array}{l}\text { Intra good } \\
\text { classifications }\end{array}$ & $\begin{array}{l}234 \text { on } 240 \\
(97.5 \%)\end{array}$ & $\begin{array}{l}394 \text { on } 400 \\
(98.5 \%))\end{array}$ & $\begin{array}{l}782 \text { on } 800 \\
(97.75 \%)\end{array}$ \\
\hline $\begin{array}{l}\text { Extra good } \\
\text { classification }\end{array}$ & $\begin{array}{l}14145 \text { on } 14160 \\
(99.9 \%)\end{array}$ & $\begin{array}{l}39570 \text { on } 39600 \\
(99.9242 \%)\end{array}$ & $\begin{array}{l}159021 \text { on } \\
159200 \\
(99.8876 \%))\end{array}$ \\
\hline \multicolumn{4}{|l|}{ Ideal rates } \\
\hline $\begin{array}{l}\text { Best accuracy } \\
\text { found (for } \\
\text { threshold) }\end{array}$ & $\begin{array}{l}98.8806 \% \\
(0.403)\end{array}$ & $\begin{array}{l}99.3851 \% \\
(0.4953)\end{array}$ & $\begin{array}{l}98.8706 \% \\
(0.4605)\end{array}$ \\
\hline $\begin{array}{l}\text { Intra good } \\
\text { classifications }\end{array}$ & $\begin{array}{l}235 \text { on } 240 \\
(97.9167 \%)\end{array}$ & $\begin{array}{l}396 \text { on } 400 \\
(99 \%)\end{array}$ & $\begin{array}{l}784 \text { on } 800 \\
(98 \%)\end{array}$ \\
\hline $\begin{array}{l}\text { Extra good } \\
\text { classifications }\end{array}$ & $\begin{array}{l}14138 \text { on } 14160 \\
(99.8 \%)\end{array}$ & $\begin{array}{l}39509 \text { on } 39600 \\
(99.7702 \%)\end{array}$ & $\begin{array}{l}158788 \text { on } \\
159200 \\
(99.7412 \%)\end{array}$ \\
\hline
\end{tabular}

\section{References}

[1] Flom, L.; Safir, A., "Iris Recognition System”, US Patent 4.641.349, Feb 1987.

[2] Daugman, J., Downing, C., "Epigenetic Randomness, Complexity, and Singularity of Human Iris Patterns", Proceedings of the Royal Society, Biological Sciences 268, pp. 1737-1740, 2001.

[3] Daugman, J., "The importance of being random: Statistical principles of iris recognition", Pattern Recognition, Vol.36, N.2, pp. 279-291, 2003.

[4] Libor Masek, "Recognition of Human Iris Patterns for Biometric Identification", the University of Western Australia, 2003. 
[5] Institute of Automation - Chinese Academy of Sciences, "Note on CASIA-IrisV3", http:/www.CBSR.IA.AC.CN/irisdatabase.htm, 2006.

[6] Daugman, J., "New Methods in Iris Recognition", IEEE Transactions on systems, man, and cybernetics - part b: cybernetics, vol. 37, pp. 11671175, 2007. 